\title{
Recurrent mechanical complications in an implant-supported fixed complete denture: a clinical report
}

Maria Paula de Lima Coltro ${ }^{\mathrm{a}}$, Thaisa Barizan Bordin ${ }^{\mathrm{b}}$, Luciano Costa Petri ${ }^{\mathrm{c}}$, Ahmet Ozkomur $^{\mathrm{d}}$, Rosemary Sadami Arai Shinkai

\begin{abstract}
INTRODUCTION: Several factors can lead to mechanical complications in implant-supported fixed complete dentures (IFCD).

CASE DESCRIPTION: This clinical report presents a clinical case of a maxillary IFCDP with recurrent mechanical complications and a possible causal interaction between patient's intrinsic characteristics (bruxism and high occlusal force) and technical procedures (framework design, occlusal adjustment, interocclusal splint, and posterior occlusal support).

CONCLUSION: The 3-year follow-up findings highlight the need for a comprehensive and systemic approach to manage a challenging case of an IFCD patient with moderate bruxism and high occlusal force.
\end{abstract}

Keywords: implant-supported fixed complete dentures; complications; occlusion; design.

\section{Complicações mecânicas recorrentes em uma prótese total fixa implantossuportada: relato de caso clínico}

\section{RESUMO}

INTRODUÇÃO: Vários fatores podem levar a complicações mecânicas em próteses totais fixas implantossuportadas (PTFI)

RELATO DO CASO: Este relatório clínico apresenta um caso clínico de PTFI maxilar com complicações mecânicas recorrentes e uma possível interação causal entre as características intrínsecas do paciente (bruxismo e exacerbada força oclusal) e procedimentos técnicos (desenho da infra-estrutura metálica, ajuste oclusal, placa interoclusal e suporte oclusal posterior)

CONCLUSÃO: Os resultados de acompanhamento de 3 anos ressaltam a necessidade de uma abordagem abrangente e sistêmica para gerenciar um caso desafiador de um paciente com PTFI com bruxismo moderado e exacerbada força oclusal.

Palavras-chave: prótese total fixa implantossuportada; complicações; oclusão; desenho. a Doctorate Student in Dentistry, Pontifical Catholic University of Rio Grande do Sul, Porto Alegre, Brazil. ${ }^{\mathrm{b}}$ Assistant Professor, Tufts University School of Dental Medicine, Boston, USA

${ }^{c}$ Private Practice, Porto Alegre, Brazil

${ }^{d}$ Associate Professor, Postgraduate Program in Dentistry, Lutheran University of Brazil, Canoas Brazil

e Professor, Postgraduate Program in Dentistry, Pontifical Catholic University of Rio Grande do Sul, Porto Alegre, Brazil 


\section{INTRODUCTION}

Proper planning, execution and control are fundamental steps for the long-term success of the oral rehabilitation treatment. Clinical studies with 5- to 15-year follow-up show that the most frequent problems in implant-supported fixed complete dentures (IFCD) are fracture and wear of the artificial teeth and veneer material, peri-implantitis, loss of access hole filling, and loosening of abutments and screws $[1,2]$. The rate of mechanical complications varies from $9.5 \%$ to $39 \%$ in observations of six months to five years $[3,4,5]$. In metal-resin IFCD, fracture and wear of the resin veneer had the highest incidence over 15 years [2,6,7]. Therefore, most problems are mechanical complications, i.e., events with damage to the artificial teeth, the implant components, or the framework, which are often repairable [8].

Complications in IFCD may be related to biological and mechanical variables. High masticatory forces were associated with increased rates of mechanical complications [8], and recurrent problems with unbalanced occlusion or centric/eccentric premature contacts [9]. Therefore, presence of bruxism and unbalanced occlusion may be risk factors for mechanical complications and biological failures in IFCD.

This report describes the clinical solution of recurrent complications in a maxillary IFCD and possible interactions between patient's factors and technical procedures during a 3-year follow-up.

\section{CASE DESCRIPTION}

A 77-year-old male patient was treated at the university dental clinic following standard clinical and laboratory procedures, in accordance with the decision-making criteria to restore the edentulous maxilla [10] with an IFCD (Fig. 1). In the mandible, the patient had natural teeth up to the premolars with no use of partial dentures to replace the missing molars due to financial constraints. The patient voluntarily signed an informed consent form to participate in a cohort study on IFCD survival, which was approved by the

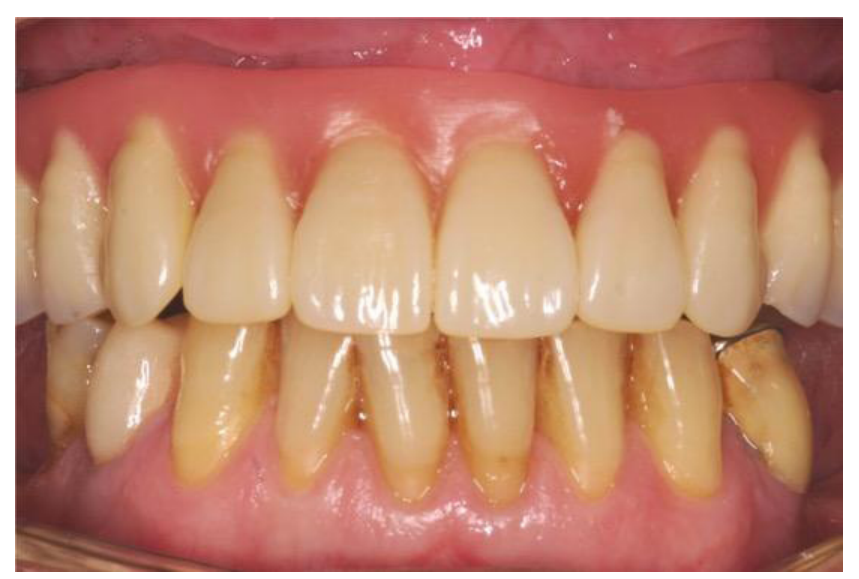

Figure 1. Delivery of the maxillary implant-supported fixed complete denture. institutional review board. As part of the study sample, the patient also gave informed consent for scientific publication of his clinical case. The study was approved by CEP-PUCRS (Of. CEP 1296/08) and registered by SISNEP (CAAE 0348.0.002.000-08).

The IFCD was fabricated over six implants with external hexagonal platform $\left(\right.$ Neodent $^{\circledR}$, Curitiba, Brazil) without the use of bone grafts. A licensed commercial laboratory performed all the technical steps for the IFCD fabrication using Soluut $\left(\operatorname{Kota}^{\circledR}\right.$, São Paulo, Brazil) acrylic teeth. The average thickness for the esthetic veneer material and artificial teeth (distance between the metallic framework and the mandibular teeth) was $5.9 \mathrm{~mm}$, and the average height of the metallic retention pins for the denture teeth was $1.8 \mathrm{~mm}$.

The patient self-reported presence of nocturnal bruxism in a questionnaire modified from Winocur et al. [11] The BiteStrip $^{\circledR}$ device (Scientific Laboratory Products, Ltd., Tel Aviv, Israel) showed some nocturnal masseter contractions classified as possible moderate bruxism [12]. The maximum bite force (MBF) recorded by a compressive force transducer [13] was $583.6 \mathrm{~N}$. No orofacial pain nor motor limitation were reported.

The distribution of occlusal forces was recorded with the T-Scan III system (TekScan Inc.) in maximum intercuspal position, right and left laterotrusion and protrusion. Before adjustment, more than $70 \%$ of the force in maximum intercuspal position was concentrated on the right side, mainly in the maxillary right first premolar (28\%) and maxillary right second premolar (21\%). An occlusal interference on the maxillary right first premolar was recorded during excursive movement to the left side and adjusted (Fig. 2).

\section{Mechanical complications and clinical solution}

Complications were verified by clinical and radiographic exams. Five mechanical complications in the IFCD occurred during the 3-year follow-up period:

1. Two weeks after the IFCD delivery, the patient returned because the right lateral incisor tooth was displaced. The artificial teeth was fixed to the denture in a chairside session.

2. Two months later (74 days after the IFCD delivery), the left lateral incisor fell out and was repositioned in the IFCD in a chairside session.

3. Two weeks later, the right lateral incisor came loose and fell out again. Because of these short-term, recurrent teeth displacement, all artificial teeth were replaced with a new set in the laboratory. An interocclusal splint was fabricated, and the height of the mandibular canines was increased with direct composite resin to improve the canine guidance during lateral movements.

4. Two years after the IFCD delivery, the right canine fell out and was repositioned in a chairside session.

5. Six months later (2.5 years after the IFCD delivery), the right first premolar fell out and was fixed in a chairside session. By that time, the patient was in treatment to receive implant-supported fixed partial dentures to replace the mandibular missing teeth (left 
second premolar, right first and second molars). A new adjustment distributed the occlusal loads according to a balanced occlusion, with occlusal contacts more evenly distributed along anterior and posterior teeth, including molars. The artificial teeth had reduced occlusal platform. A new interocclusal splint was fabricated.
In the 3-year follow-up, the distribution of the occlusal forces still was balanced as recorded by means of the T-Scan III with no further complications (Fig. 3). Even with multiple complications and need of repair overtime, the patient always reported more satisfaction with the IFCD in comparison with his old maxillary denture.

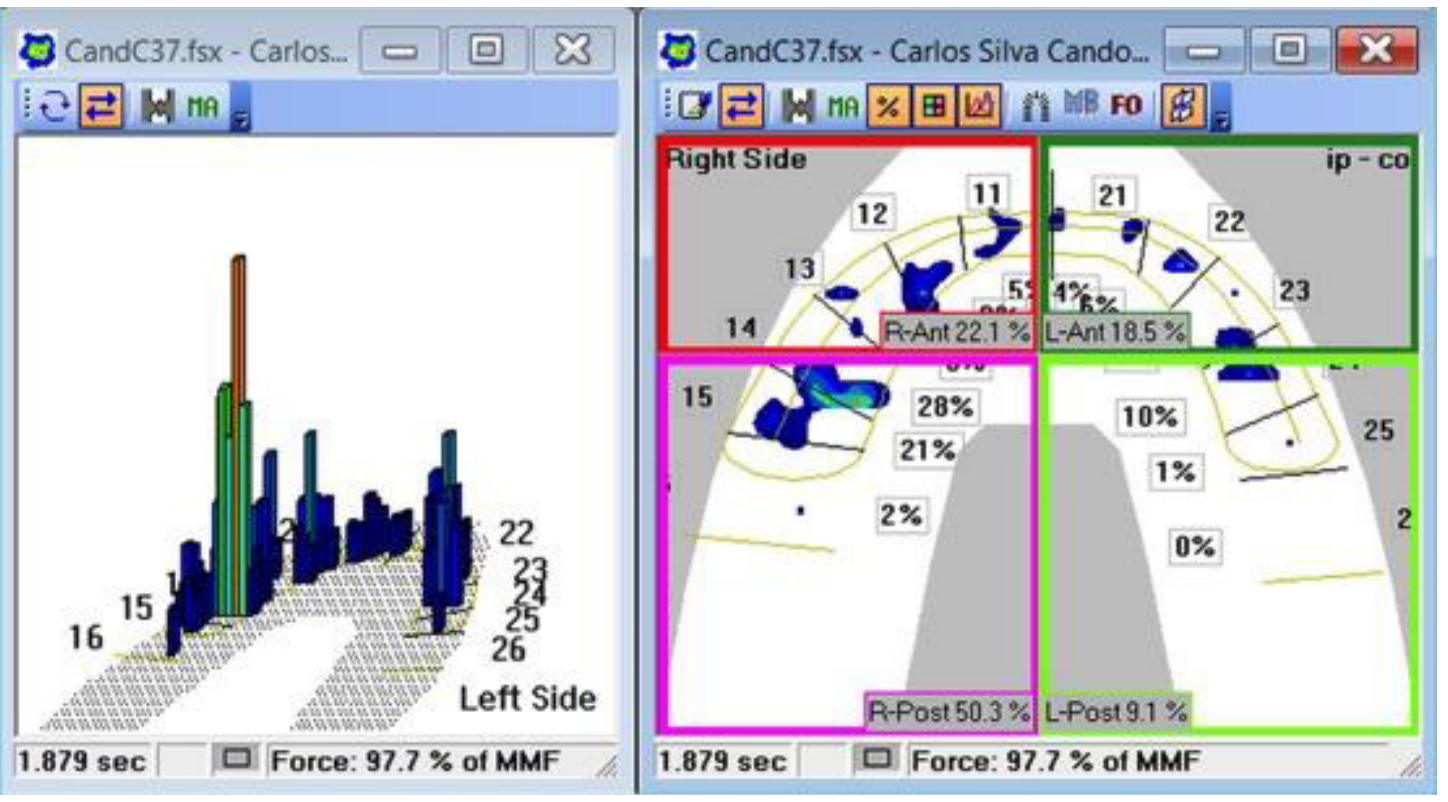

Figure 2. Data analysis in T-Scan III software before occlusal adjustment. Maximum intercuspal position was recorded immediately after the implant-supported fixed complete denture delivery.

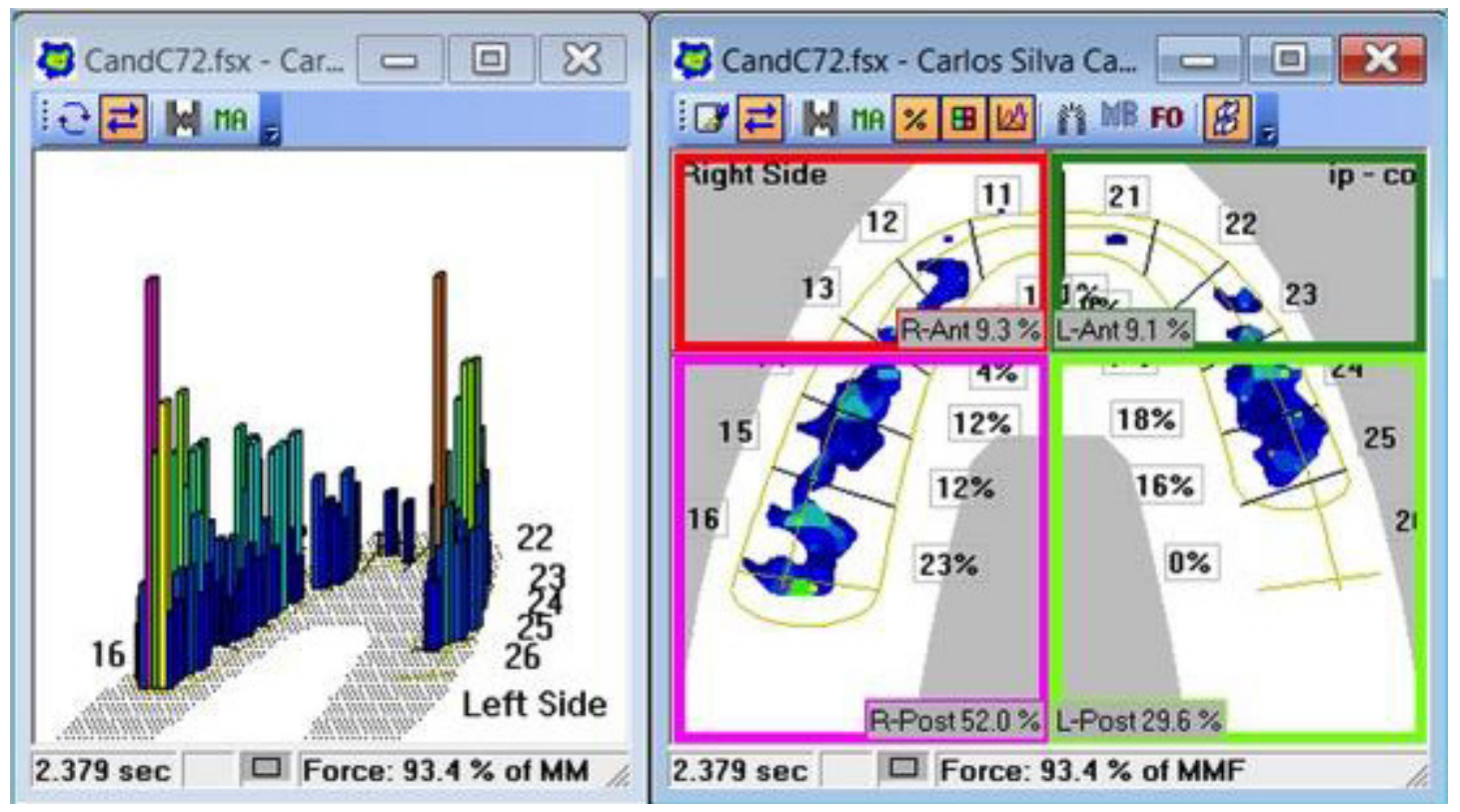

Figure 3. Data analysis in T-Scan III software at the 3-year follow-up of the implant-supported fixed complete denture. Maximum intercuspal position was recorded immediately after the installation of crowns on the mandibular posterior implants and general occlusal adjustment. 


\section{DISCUSSION}

The multiple IFCD mechanical complications in this patient probably resulted from an interaction of intrinsic (patient-mediated) and extrinsic (clinician-mediated) factors, such as presence of bruxism, posterior reduced mandibular arch, and framework design.

The recurrent displacement of different artificial teeth from the resin base suggests a combination of factors that might not have generated similar problems in a less challenging clinical situation. The displaced artificial teeth had mechanical retention by metallic pins from the framework bar, but these were insufficient for effective retention in this patient. In cases of significant bruxism and strong occlusal force, long metallic pins seem to be necessary for retention of the artificial teeth, irrespective of the amount of acrylic resin around the teeth. On the other hand, the mechanical retentions on the metallic framework worked well for the retention of the acrylic resin base.

Using the T-Scan III system, the distribution of occlusal forces can be analyzed in centric position and in excursive movements, allowing relative quantification of occlusal forces. The patient had group function with a mutually protected occlusion in lateral movements. During lateral excursion around $20 \%$ to $30 \%$ of the occlusal loading was recorded on the teeth which became loose. But during the protrusion motion, almost $90 \%$ of the force was concentrated in the maxillary incisors. However, there is still no consensus in the literature regarding the best type of occlusion for each type of implant-supported denture [10]. The concept of shortened dental arch did not worked well for this patient, and the distribution of occlusal forces was greatly improved after the replacement of the mandibular molars. Also, the use of an interocclusal splint should be reinforced for patients with bruxism whenever possible. Studies show that there is a significantly higher risk of fractures in dentures of patients with bruxism, when an interocclusal splint is not used [14-18].

This case with multiple and recurrent mechanical complications suggests a possible negative association of the metallic superstructure design, presence of bruxism and distribution of occlusal forces. While the framework design can be easily modified to provide additional mechanical retention for the artificial teeth, the presence of bruxism poses a clinical challenge with only palliative solution so far.

\section{CONCLUSION}

This case report shows the need of individualized framework design and distribution of occlusal load to minimize the occurrence of complications in IFCD. Artificial teeth should have individual inner metallic retention to reduce the risk of displacement under challenging occlusion, irrespective of the amount of acrylic resin around the teeth. The early identification and management of risk factors may prevent complications in IFCD and reduce costs and nonscheduled visits to the dentist.

\section{REFERENCES}

1. Pjetursson BE, Thoma D, Jung R, Zwahlen M, Zembic A. A systematic review of the survival and complication rates of implant-supported fixed dental prostheses (FDPs) after a mean observation period of at least 5 years. Clin Oral Implants Res 2012;23:22-38. https://doi.org/10.1111/ j.1600-0501.2012.02546.x

2. Jemt T, Johansson J. Implant treatment in the edentulous maxilla: a 15-year follow-up study on 76 consecutive patients provided with fixed prostheses. Clin Implant Dent Relat Res 2006;8:61-9. https://doi.org/10.1111/j.17088208.2006.00003.x

3. Duncan JP, Nazarova E, Vogiatzi T, Taylor TD. Prosthodontic complications in a prospective clinical trial of single-stage implants at 36 months. Int J Oral Maxillofac Implants 2003;18:561-5.

4. De Boever AL, Keersmaekers K, Vanmaele G, Kerschbaum T, Theuniers $G$, De Boever JA. Prosthetic complications in fixed endosseous implantborne reconstructions after an observations period of at least 40 months. J Oral Rehabil 2006;33:833-9. https://doi.org/10.1111/j.1365-2842.2006. 01638.x

5. Wahlstrom M, Sagulin GB, Jansson LE. Clinical follow-up of unilateral fixed dental prosthesis on maxillary implants. Clin Oral Implants Res 2010; 21:1294-300. https://doi.org/10.1111/j.1600-0501.2010.01948.x

6. Jemt T, Johansson J. Implant treatment in the edentulous maxilla: a 15-year follow-up study on 76 consecutive patients provided with fixed prostheses. Clin Implant Dent Relat Res 2006;8:61-69. https://doi.org/10.1111/j.17088208.2006.00003.x

7. Bozini T, Petridis H, Garefis K, Garefis P. A meta-analysis of prosthodontic complication rates of implant-supported fixed dental prostheses in edentulous patients after an observation period of at least 5 years. Int $J$ Oral Maxillofac Implants 2011;26:304-318

8. Papaspyridakos P, Chen CJ, Chuang SK, Weber HP, Gallucci GO. A systematic review of biologic and technical complications with fixed implant rehabilitations for edentulous patient. Int J Oral Maxillofac Implants 2012;27:102-10

9. Sheridan RA, Decker AM, Plonka AB, Wang HL. The role of occlusion in implant therapy: a comprehensive updated review. Implant Dent 2016;25:829-38. https://doi.org/10.1097/ID.0000000000000488

10. Sadowsky SJ, Fitzpatrick B, Curtis DA. Evidence-based criteria for differential treatment planning of implant restorations for the maxillary edentulous patient. J Prosthodont 2015:24:433-46. https://doi. org/10.1111/jopr.12226

11. Winocur E, Uziel N, Lisha T, Goldsmith C, Eli I. Self-reported bruxism associations with perceived stress, motivation for control, dental anxiety and gagging. J Oral Rehabil 2010;38:3-11. https://doi.org/10.1111/j.13652842.2010.02118.x

12. Shochat T, Gavish A, Arons E, Hadas N, Molotsky A, Lavie P, Oksenberg A. Validation of the BiteStrip screener for sleep bruxism. Oral Surg Ora Med Oral Pathol Oral Radiol Endod 2007;104(3):e32-9. https://doi. org/10.1016/j.tripleo.2007.03.009

13. Hatch JP, Shinkai RS, Sakai S, Rugh JD, Paunovich ED. Determinants of masticatory performance in dentate adults. Arch Oral Biol 2001;46:641-8 https://doi.org/10.1016/S0003-9969(01)00023-1

14. Kinsel RP, Lin D. Retrospective analysis of porcelain failures of metal ceramic crowns and fixed partial dentures supported by 729 implants in 152 patients: patient-specific and implant-specific predictors of ceramic failure. J Prosthet Dent 2009;101:388-94. https://doi.org/10.1016/S0022 3913(09)60083-4

15. Maló P, Nobre Md, Lopes A. The rehabilitation of completely edentulous maxillae with different degrees of resorption with four or more immediately loaded implants: a 5-year retrospective study and a new classification. Eur J Oral Implantol 2011;4:227-43.

16. Johansson A, Omar R, Carlsson GE. Bruxism and prosthetic treatment: a critical review. J Prosthodont Res 2011;55:127-36. https://doi. org/10.1016/j.jpor.2011.02.004

17. Lin WS, Ercoli C, Lowenguth R, Yerke LM, Morton D. Oral rehabilitation of a patient with bruxism and cluster implant failures in the edentulous maxilla: a clinical report. J Prosthet Dent 2012;108:1-8. https://doi.org/10.1016/ S0022-3913(12)00086-8

18. Winocur E, Uziel N, Lisha T, Goldsmith C, Eli I. Self-reported bruxism associations with perceived stress, motivation for control, dental anxiety and gagging. J Oral Rehabil 2010;38:3-11. https://doi.org/10.1111/j.13652842.2010.02118.x 